Original Research Paper

\title{
The -863 TNF- $\alpha$ Polymorphism and Primary Open Angle Glaucoma in Egyptians
}

\author{
${ }^{1}$ Walaa Bayoumie Abdulwahhab El Gazzar, ${ }^{1}$ Shaymaa Mohamed Abd El Rahman, \\ ${ }^{2}$ Mohamed Nagy Elmohamady, ${ }^{2}$ Ahmed Mohamed Saeed and ${ }^{2}$ Usama Shalaby \\ ${ }^{I}$ Department of Biochemistry and Molecular Biology, Faculty of Medicine, Benha University, Egypt \\ ${ }^{2}$ Department of Ophthalmology, Benha University Hospital, Faculty of Medicine, Benha University, Egypt
}

Article history

Received: 31-03-2017

Revised: $24-05-2017$

Accepted: 30-05-2017

Corresponding Author: Walaa Bayoumie Abdulwahhab El Gazzar Department of Biochemistry and Molecular biology, Faculty of Medicine, Benha University, Egypt

E-mail: bioch_2004@yahoo.com

\begin{abstract}
Growing evidence indicates that TNF-alpha is involved in the pathogenesis of POAG in several ways, primarly by induction of retinal ganglion cells apoptosis and therefore optic nerve degeneration. TNF-alpha and POAG relationship has been studied at the genetic level with variable results in different populations. The transcription rate and the release of the TNF-alpha cytokine have been reported to be affected by polymorphisms in the promoter of the TNF- alpha gene. Polymorphisms at positions -238 and -308 are the most frequent studied. Another polymorphism, at the position -863 in the promoter region, has been less studied, but a homozygous AA allele appears protective in a Chinese population. Our aim was to assess the potential association of $-863 \mathrm{C} / \mathrm{A}$ TNF-alpha gene promoter polymorphisms with POAG in an Egyptian group of subjects. Genotyping of the TNF-alpha (-863) polymorphism was done for 228 POAG patients and 230 control subjects using the PCRbased, Restriction Fragment Length Polymorphism (RFLP) assay. TNFalpha (-863) A/A genotype was absent in both groups. There was no significant difference between both groups as regards to TNF- $\alpha(-863) \mathrm{A}$ allele carriage (6.14 versus $10.43 \% ; \mathrm{p}=0.099)$ ). Also the genotype TNF- $\alpha$ $(-863) \mathrm{C} / \mathrm{C}$ and the frequency of the tumor necrosis factor-alpha $(-863) \mathrm{C}$ allele did not significantly differ between both groups (93.86 versus $89.57 \%$; $p=0.099)$ and 96.93 versus $94.78 \% ; p=0.107)$ respectively. Our data indicated that the TNF-alpha (-863) a allele is not linked with primary open angle glaucoma protection among Egyptian patients.
\end{abstract}

Keywords: Polymorphism, PCR-RFLP, POAG, TNF- $\alpha$, Glaucoma

\section{Introduction}

Glaucoma is a progressive optic neuropathy associated with Retinal Ganglion Cell (RGC) degeneration-optic disc cupping and defects of the visual field. A crucial and common risk factor is Intraocular Pressure (IOP) elevation and about seventy million people have glaucoma throughout the world (Quigley and Broman, 2006). Primary Open Angle Glaucoma (POAG) and Primary Angle Closure Glaucoma (PACG) are subdivisions of Primary glaucoma (Shields, 2005), with POAG being more common in most populations, (AAOGP, 2010). The mechanism is multi factorial and complex neurodegeneration results from interactions between genetic, epigenetic, aging-related and other factors (Yang et al., 2011).
Tumor necrosis factor-alpha is implicated in various inflammatory and immune reactions. It is mainly secreted by monocytes, but significant amounts are secreted also by other cell types (Beutler and Cerami, 1989). The clinical and investigational studies about the role of tumor necrosis factor-alpha in the etiology of glaucoma denote that ischemic glial cells release tumor necrosis factor-alpha, to prime retinal ganglion cells apoptosis and the degree of optic nerve degeneration is matched with the tumor necrosis factor-alpha expression from the retina and optic nerve head (Tezel and Wax, 2000).

The upstream region of the TNF-alpha locus at the Major Histocompatibility Complex (MHC) class III region on chromosome 6 p 21.3 is polymorphic and related to modifications in TNF-alpha production 
(Hajeer and Hutchinson, 2001). While there may be some control on the tumor necrosis factor-alpha gene transcription, promoter region polymorphisms have been related to TNF-alpha gene expression or protein synthesis (Skoog et al., 1999) although with inconstant results in various populations worldwide. The most repeatedly investigated Single Nucleotide Polymorphisms (SNPs) in the upstream region are those at positions -238 and -308 . A third SNP at position -863 has been studied less extensively (Lee and Song, 2015; Simionescu et al., 2015; Al-Dabbagh et al., 2011). The aim of this study was to determine whether this SNP affected the susceptibility of Egyptian patients to primary open angle glucoma.

\section{Methods}

\section{Study Subjects}

This study included 228 primary open angle glaucoma patients and 230 healthy individuals as a control group. All participants were unrelated Egyptians matched for gender and age. The inclusion criteria were distinguishing markers in the monocular field of according to Anderson's criteria for minimal glaucoma abnormality, optic nerve heads cupping, open Anterior Chamber (AC) angles on gonioscopy, IOP of $\geq 21 \mathrm{mmHg}$ at a point in the path of the disease and the absence of secondary causes of glaucoma (Suzumura et al., 2011). Subjects with a previous history of ocular traumatic injury or surgery or other ocular or systemic diseases were excluded. A written informed agreement was obtained as per the Declaration of Helsinki.

\section{Clinical Evaluation}

We took a thorough history including age, gender, duration of primary open angle glucoma, medications and previous surgeries. We did a comprehensive ophthalmic examination for all subjects in the form of unaided and corrected visual acuity, slit lamp biomicroscopy, IOP measuring and indirect ophthalmoscopy. For the glaucoma group only, the central 30 degrees of the visual field was evaluated using Humphrey perimeter and he optic nerve head evaluation was done using Ocular Coherence Tomography (OCT).

\section{DNA Preparation and Genotyping}

We collected venous blood sample in $5 \mathrm{~mL}$ EDTA tubes then genomic DNA isolation was done using the QIAamp. DNA Blood MiniKit, (QIAGEN, Valencia, CA). The DNA concentration and purity was estimated by a Nanodrop spectrophotometer (Optima SP-3000+, Japan). Using a Nanodrop spectrophotometer (Optima SP-3000+, Japan), we estimated the concentration and the purity of DNA.
TNF-alpha (-863C/A) polymorphism was genotyped by PCR and detected by restriction fragment length polymorphism (PCR-RFLP) assay. The primers were: forward (5' -GGC TCT GAG GAA TGG GTT AC-3') and reverse (5' -CTA CAT GGC CCTGTC TTC GTT ACG 3'). DNA samples were amplified in a total reaction volume $25 \mu \mathrm{L}$ aliquots containing $12.5 \mu \mathrm{L}$ Taq PCR Master Mix (QIAGEN, Valencia, CA), $1 \mu \mathrm{L}$ of each primer $(0.4 \mu \mathrm{M}$ final conc.), extracted DNA to 0.1 microgram final conc., RNase-free water to a total volume of $25 \mu \mathrm{L}$. The G- storm thermal cycler (Gene technologies. Ltd, England) was used for the amplification process according to the following program: $95^{\circ} \mathrm{C}, 1 \mathrm{~min}$, (Initial denaturation) $-95^{\circ} \mathrm{C}, 1$ min, (denaturation) $-57^{\circ} \mathrm{C}, 15 \mathrm{Sec}$, (annealing) -72 $248^{\circ} \mathrm{C}$, $45 \mathrm{Sec}$, (extension)- No. of cycles: 35 and final extension at $72^{\circ} \mathrm{C}$ for $5 \mathrm{~min}$.

Products of amplification were signified by electrophoresis on $1.5 \%$ agarose gel (stained with ethidium bromide) and gave an expected PCR product size of $125 \mathrm{bp}$ (Fig. 1), then digested with the Fast Digest Tail restriction endonuclease (Thermo-scientific -ThermoFisher Scientific Inc.). For digestion, the following reaction components were combined at room temperature: 17 $\mu \mathrm{L}$ nuclease-free water, $2 \mu \mathrm{L} 10 \mathrm{X}$ Fast Digest Buffer, $10 \mu \mathrm{L}$ PCR product and $1 \mu \mathrm{L}$ Fast Digest enzyme then mixed gently and incubated at $65^{\circ} \mathrm{C}$ in a heat block for $5 \mathrm{~min}$. The digested products were detected using electrophoresis on a $1.5 \%$ agarose gel (stained with ethidium bromide). The bands were visualized using a uv Transilluminator $(254 \mathrm{~nm}$, Alpha Inno ztechcoporation, USA), then photographed and analyzed using a digital camera (Olympus. ED lens. 6.3 megapixel, USA). Photos were transferred to computerized analysis using Gel Documentation System (Alpha Innotech, USA).

The TaiI restriction enzyme cleaved the mutated (-863 A) $125 \mathrm{bp}$ allele (restriction sequence: ACGT), giving rise to fragments of 104 and $21 \mathrm{bp}$, of which only the $104 \mathrm{bp}$ fragment was detected on the gel. Thus, in subjects homozygous for the wild-type $(-863 \mathrm{C})$ allele, a single band of $125 \mathrm{bp}$ is observed; in heterozygous subjects $(-863 \mathrm{C} / \mathrm{A})$, two bands of 104 and $125 \mathrm{bp}$; and in subjects homozygous for the mutated (-863A) allele, a band of $104 \mathrm{bp}$ is observed (Fig. 2). Selected samples underwent sequencing to ensure accuracy.

\section{Statistical Analysis}

All the analyses were done using SPSS, 20.0 (SPSS Inc., IBM, USA) and results were stated as mean \pm Standard Deviation (SD). To assess the statistical differences between the categorical data, we employed the chi-squared test. The independent sample $t$ test was used to compare variables. Any $\mathrm{P}$ value $\leq 0.05$ reflected a statistically significant value. 


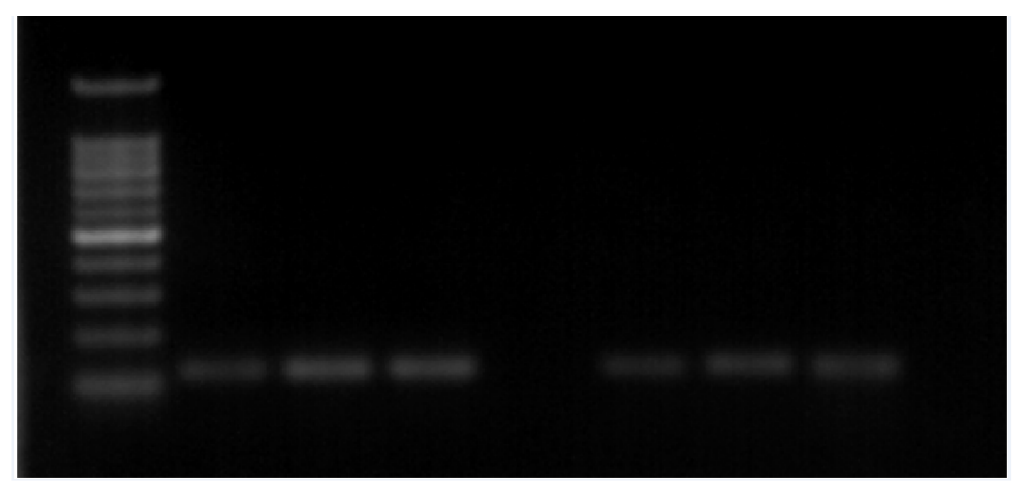

Fig. 1. Gel electrophoresis for the PCR product of the target genomic region

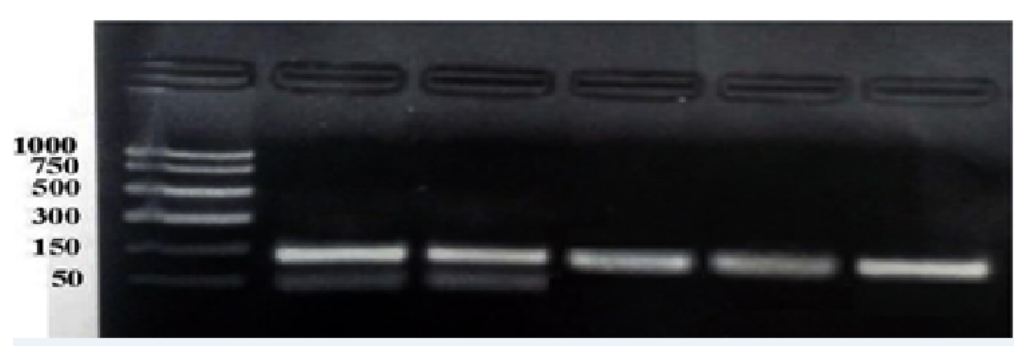

Fig. 2. Gel electrophoresis for the PCR product of the target genomic region after digestion with the fast digest Tail restriction endonuclease

Table 1.Genotype and allele frequencies of TNF- $\alpha-863 \mathrm{C} / \mathrm{A}$

\begin{tabular}{|c|c|c|c|c|c|}
\hline TNF- $\alpha-863$ polymorphism & Patients with POAG & Control subjects & Odds ratio & $\mathrm{X}^{\wedge} 2$ value & $\mathrm{p}$-value \\
\hline Genotype & $(\mathrm{n}=228)$ & $(\mathrm{n}=230)$ & $(95 \% \mathrm{CI})$ & & \\
\hline $\mathrm{CC}$ & $214(93.86 \%)$ & $206(89.57 \%)$ & 1.781 & 2.775 & 0.099 \\
\hline $\mathrm{CA}$ & $14(6.14 \%)$ & $24(10.43 \%)$ & $(0.90-3.54)$ & & \\
\hline AA & $0(0.0 \%)$ & $0(0.00 \%)$ & & & \\
\hline \multicolumn{6}{|l|}{ Allele frequency } \\
\hline $\mathrm{C}$ & $442(96.93 \%)$ & 436 (94.78\%) & 1.738 & 2.655 & 0.107 \\
\hline A & $14(3.07 \%)$ & $24(5.22 \%)$ & $(0.89-3.40)$ & & \\
\hline \multicolumn{6}{|l|}{ Aallele carriage } \\
\hline $\mathrm{AA}+\mathrm{CA}$ & $14(6.14 \%)$ & $24(10.43 \%)$ & 1.781 & 2.775 & 0.099 \\
\hline $\mathrm{CC}$ & $214(93.86 \%)$ & $206(89.57 \%)$ & $(0.90-3.54)$ & & \\
\hline
\end{tabular}

Numbers for genotypes are $n(\%)$

\section{Results}

Our study included 228 Egyptian glaucoma patients (97 males and 131 females) and 230 healthy individuals (101 males and 129 females). Mean age was $67.4 \pm 5.9$ years in the primary open angle glaucoma group and $66.9 \pm 4.3$ years in the control group.

Genotype and allele frequencies of TNF-alpha-863C/A are shown in Table 1. In both groups none of the studied subjects were homozygous for the $\mathrm{A} / \mathrm{A}$ allele and the $\mathrm{A}$ allele carriage in the primary open angle glaucoma group and the control group was 6.14 and $10.43 \%$ respectively (No statistically significant difference was found; $p=0.099$ ) and so the frequency of the TNFalpha (-863) A allele did not significantly vary between the two groups (3.07 versus $5.22 \%, \mathrm{p}=0.107)$. The
$\mathrm{C} / \mathrm{C}$ genotype in the primary open angle glaucoma group and the control group was 93.86 and $89.57 \%$ respectively $(p=0.099)$ and the frequency of the tumor necrosis factor-alpha (-863) C allele did not significantly vary between both groups (96.93 versus $94.78 \% ; p=0.107$ ) respectively.

\section{Discussion}

This work is the first to address the role of the tumor necrosis factor-alpha (-863) gene polymorphisms in Egyptian patients with primary open angle glucoma. Others have studied the G-380 SNP (Hamid et al., 2016) and found that it was related significantly with primary open angle glaucomain another Egyptian population. 
In our work, we determined the genotypes of the TNF-alpha (-863) polymorphisms in 228 patients with primary open angle glaucoma and 230 control subjects, matched for age and gender. Allelic frequencies and genotype distributions did not significantly differ between the 2 groups. This is in line with Funayama and associates (Funayama et al., 2004) who investigated the association between sequence variation in the Optineurin gene and the polymorphisms in the TNF-alpha promoter region, at positions $-308,-857$ and -863 in Japanese POAG patients. Optineurin expression is induced by tumor necrosis factor-alpha and interferes with adenoviral E3$14.7 \mathrm{~K}$ protein which safeguards cells from the neurodegenerative effect of TNF- $\alpha$. Funayama and associates found that there was no significant difference in genotype or allelic frequency was observed between POAG patients and Japanese control for the 3 SNPs of TNF-alpha, they also observed that POAG Patients who were TNF-alpha $-863 \mathrm{~A}$ and optineurin/603A carriers had significantly worse $(\mathrm{p}=$ $0.026)$ visual field scores than those who were TNF alpha-863 A and non-optineurin/603 $\mathrm{A}$ carriers and this supports our findings that the TNF-alpha -863A allele is not linked with primary open angle glaucoma protection among Egyptian patients .

On the other side, our results are opposite to those of (Wang et al., 2012) who stated that the TNF-alpha $-863 \mathrm{~A}$ allele is linked with primary open angle glaucoma protection in the Chinese as the AA genotype was less common in primary open angle glucoma patients $(7 \%)$ than in controls $(11 \%),(p=0.037)$ and the TNF-alpha $-863 \mathrm{~A}$ allele frequency was significantly decreased in the primary open angle glaucoma group (22 versus $30 \%, p=0.007$ ) while our results showed absence of the homozygous AA allele in the two groups and no statistically significant difference was found as regard to the A allele carriage $(p=0.099)$ and A allele frequency $(\mathrm{p}=0.107)$. These contradictory outcomes may be owing to variable genotype distributions among different populations.

Our results suggest that the TNF-alpha $-863 \mathrm{~A}$ allele is not linked with primary open angle glaucoma protection, but we do not exclude the role of TNF-alpha -863 polymorphism in the glaucoma pathogenesis as neurodegeneration results from interactions between genetic and epigenetic factors and so further studies that correlate the association of TNF-alpha -863 polymorphism with polymorphisms in other genes impacted in POAG like Optineurin gene should be followed. Our work was restricted by the relatively small number of subjects and so, population-based studies are needed.

\section{Acknowledgment}

This research was performed using the equipments and instruments of the Molecular Biology Unit (MBU)/
Faculty of Medicine/Benha University, in collaboration with the Ophthalmology department/Benha University Hospital/Faculty of Medicine/Benha University/Egypt, for collecting the clinical samples and the required data.

\section{Funding Details}

This work was financially supported by the Molecular Biology Unit, Faculty of Medicine, Benha University, Egypt, as well as author's contributions.

\section{Author's Contributions}

Walaa Bayoumie Abdulwahhab El Gazzar: Conceived and designed the research, molecular biology technique, analyzed and interpreted the data, critical revision of the manuscript and corresponding author.

Shaymaa Mohamed Abd El Rahman: Molecular biology technique, drafted the manuscript, revision of the manuscript.

Mohamed Nagy Elmohamady: Collecting samples and clinical data, writing and revision of the manuscript.

Ahmed Mohamed Saeed: Collecting samples and clinical data.

Usama Shalaby: Collecting samples and clinical data.

\section{Disclosure of Interest}

There is no conflict of interest that I should disclose.

\section{References}

Quigley, H.A. and A. Broman, 2006. The number of people with glaucoma worldwide in 2010 and 2020. Br J. Ophtalmol., 90: 262-7. DOI: 10.1136/bjo.2005.081224

Shields, M.B., 2005. Shields' Textbook of Glaucoma. 4th Edn., Lippincott Williams and Wilkins, New York.

AAOGP, 2010. Preferred practice pattern ${ }^{\circledR}$ guidelines. Primary open-angle glaucoma. American Academy of Ophthalmology, San Francisco, CA.

Yang, X., C. Luo, J. Cai, D.W. Powell and D. Yu et al., 2011. Neurodegenerative and inflammatory pathway components linked to TNF- $\alpha$ /TNFR1 signaling in the glaucomatous human retina. Invest. Ophthalmol. Vis. Sci., 52: 8442-8454. DOI: 10.1167/iovs.11-8152

Beutler, B. and A. Cerami, 1989. The biology of cachectin/TNF- a primary mediator of host response. Annu. Rev. Immunol., 7: 625-655.

Tezel, G. and M.B. Wax, 2000. Increased production of tumor necrosis factor-alpha by glial cells exposed to simulated ischemia or elevated hydrostatic pressure induces apoptosis in cocultured retinal ganglion cells. J. Neurosci., 20: 8693-700.

Hajeer, A.H. and I.V. Hutchinson, 2001. Influence of TNF-alpha gene polymorphisms on TNF-alpha production and disease. Hum. Immunol., 62: 1191-1199. PMID: 11704281 
Skoog, T., F.M. van't Hooft, B. Kallin, S. Jovinge and S. Boquist et al., 1999. A common functional polymorphism (C-->A substitution at position -863) in the promoter region of the Tumour Necrosis Factoralpha (TNF-alpha) gene associated with reduced circulating levels of TNF-alpha. Hum. Mol. Genet., 8: 1443-1449.

Lee, Y.H. and G.G. Song, 2015. TNF- $\alpha-308$ A/G and -238 A/G polymorphisms and susceptibility to glaucoma: A meta-analysis. Genet. Mol. Res., 14: 4966-4977.

Simionescu, R., A. Popa Cherecheanu, L. Voinea and R. Sfrenț-Cornățeanu, 2015. TNF- $\alpha$ Gene polymorphisms and primary open angle glaucoma in Romanian population. Rev. Romana Med. Lab, 23: 47-58. DOI: 10.1515/rrlm-2015-0004

Al-Dabbagh, N.M., N. Al-Dohayan, A. Al-Asmari, M. Arfin and M. Tariq, 2011. Association of TNF$\alpha$ and TNF- $\beta$ Gene Polymorphisms with Primary Open Angle and Primary Angle Closure Glaucoma. In: The Mystery of Glaucoma, Kubena, T. (Ed.), InTech, pp: 229-256.
Suzumura, H., K. Yoshikawa, T. Kimura and S. Yamazaki, 2011. Anderson criteria in early glaucomatous visual field defects with the SITA Standard. Nippon Ganka Gakkai Zasshi, 115: 435-439.

Hamid, M.A., L. Moemen, H. Labib, H. Helmy and T. Elsergany, 2016. Risk of open angle glaucoma due to tumor necrosis factor alpha gene polymorphisms. Electr. Phys., 8: 1978-1983. DOI: $10.19082 / 1978$

Funayama, T., K. Ishikawa, Y. Ohtake, T. Tanino and D. Kurosaka et al., 2004. Variants in optineurin gene and their association with tumor necrosis factor-alpha polymorphisms in Japanese patients with glaucoma. Invest Ophthalmol. Vis. Sci., 45: 4359-4367.

Wang, C.Y., Y.C. Shen, L.C. Wei, K.H. Lin and S.C. Feng et al., 2012. Polymorphism in the TNF$\alpha(-863)$ locus associated with reduced risk of primary open angle glaucoma. Mol. Vis., 18: 779785. PMID: 22509108 